\title{
A Rare Case of Sessile Polypoidal Xanthoma of Vocal Cord
}

Anil Kumar Jain, Sanyogita Jain, Ashish Katarkar, Noorain Alam, Nayna Lakum, Pankaj Shah, Datt Modh

\begin{abstract}
We report a rare case of sessile polypoidal xanthoma of vocal cord in a 38-year-old female, presented with complaint of hoarseness of voice for 3 months. Hopkins telescopic examination showed a sessile polyp arising from the anterior aspect of laryngeal vocal cord. With clinical diagnosis of vocal cord polyp, microlaryngeal surgery was done and tissue was sent for histopathological and culture examination. Histopathological findings showed features of polypoidal xanthoma. Culture was negative.
\end{abstract}

Keywords: Hopkins telescopic examination, Microlaryngeal surgery, Histopathological examination, Polypoidal xanthoma.

How to cite this article: J ain AK, J ain S, Katarkar A, Alam N, Lakum N, Shah P, Modh D. A Rare Case of Sessile Polypoidal Xanthoma of Vocal Cord. Int J Phonosurg Laryngol 2012;2(2): 66-68.

\section{Source of support $\mathrm{Nil}$}

Conflict of interest: None declared

\section{INTRODUCTION}

$\mathrm{X}$ anthoma is not a tumor but a benign reactive histiocytic proliferation. ${ }^{1}$ The common sites are skin and subcutis but occasionally involve the tendon or synovium. ${ }^{1}$ Only few studies of xanthoma involving the larynx have been recorded in English literature ${ }^{1-4}$ and sessile polypoidal xanthoma of larynx is extremely rare. ${ }^{1}$

\section{CASE REPORT}

A 38-year-old female presented to Department of Otorhinolaryngology with complaint of hoarseness of voice for 3 months. Hopkins telescopic examination revealed a sessile polyp on the anterior aspect of left vocal cord (Fig. 1). A provisional diagnosis of vocal cord polyp was made and excision was done by microlaryngeal surgery (M LS). Gross examination showed a mucosa covered soft polypoidal mass measuring $0.9 \mathrm{~cm}$ in diameter. Microscopic examination revealed a polypoidal mass covered by nonkeratinized stratified squamous epithelial lining. The subepithelial tissue revealed peripheral scanty fibrocollagenous tissue, blood vessels and central collection of foamy histiocytes (Figs 2 and 3) and occasional touton giant cells (Fig. 4). On the basis of these findings, a diagnosis of polypoidal laryngeal xanthoma was made. Her postoperative voice was improved. L ipid profile done after histopathological diagnosis show ed borderline high value of serum cholesterol $(2.28 \mathrm{gm} / \mathrm{l})$ and

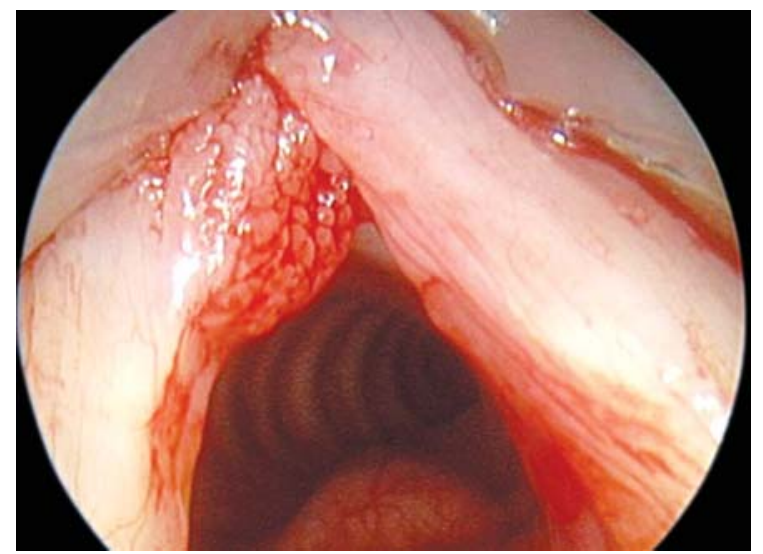

Fig. 1: Hopkins telescopic examination showed a sessile polyp arising from the anterior aspect of laryngeal vocal cord

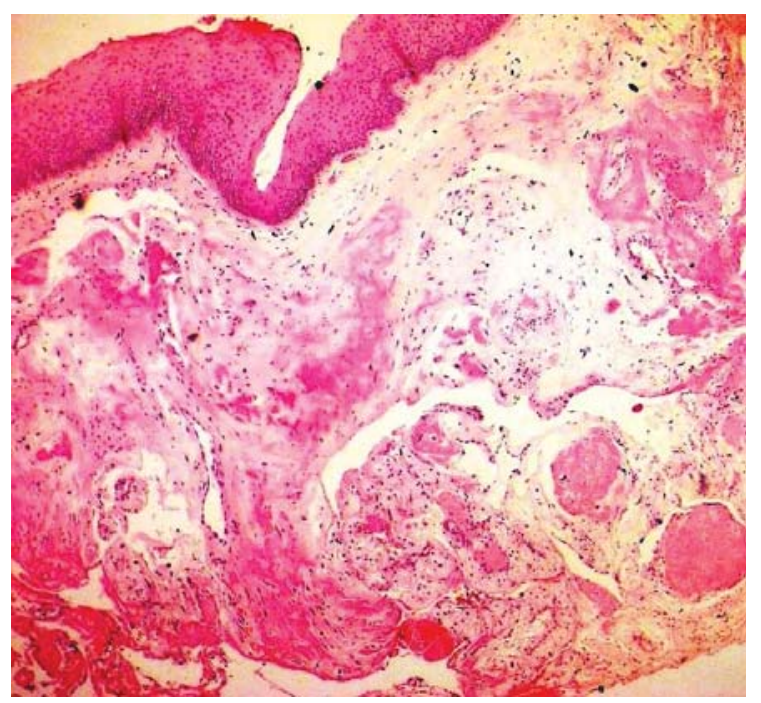

Fig. 2: Section showing stratified squamous epithelial lining with central collection of foamy histiocytes and giant cells, and peripheral scant fibrocollagenous tissue $(\mathrm{H} \& \mathrm{E} ; \times 40)$

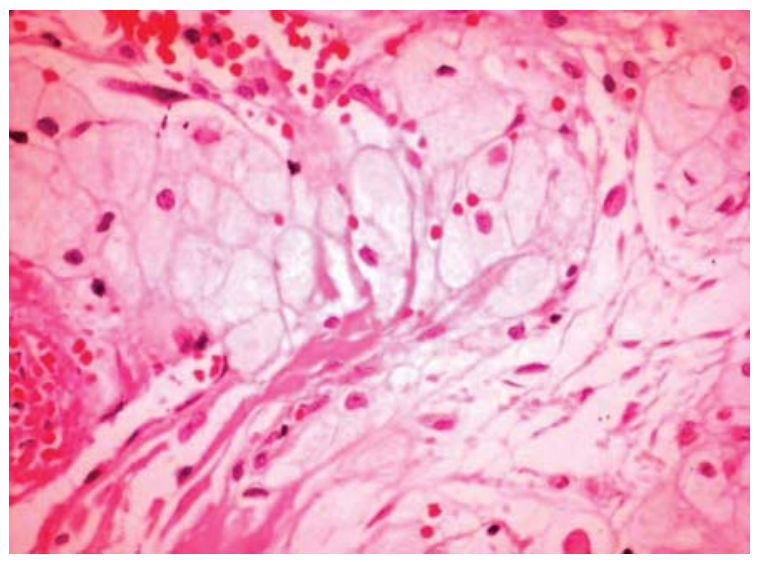

Fig. 3: Section showing collection of foamy histiocytes $(\mathrm{H} \& \mathrm{E} \times 400)$ 


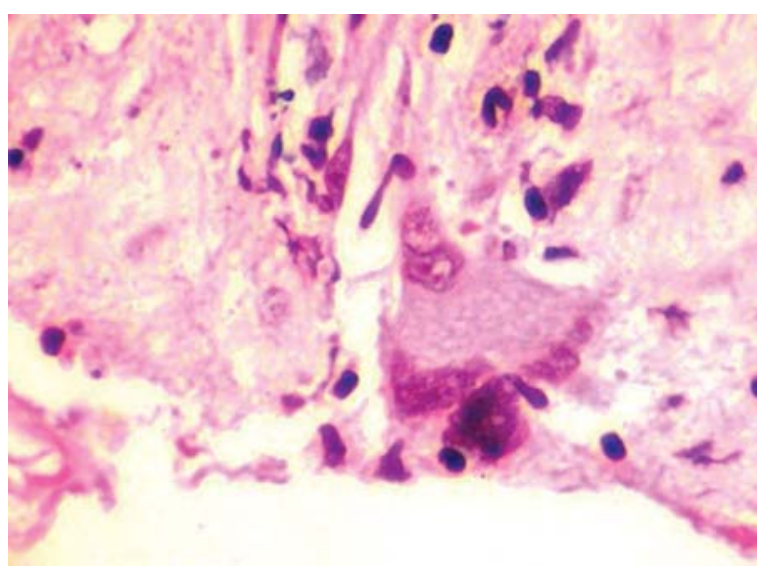

Fig. 4: Touton giant cells having cytoplasmic vacuoles and bipolar arranged nuclei (H\&E; ×400)

low density lipoprotein (LDL) (1.42 gm/l), but normal value of serum high density lipoprotein (HDL) and triglyceride. She was managed by dietary advice and clofibrate. Repeat lipid profile showed normal value after 1 month of treatment. The patient was reassured, advised to avoid voice abuse and was kept under regular follow-up. No recurrence or any cutaneous or tendinous lesion was found on 2 years of follow-up.

\section{DISCUSSION}

M ost common polypoidal lesion affecting the larynx is the laryngeal polyp. ${ }^{1} \mathrm{~L}$ aryngeal diseases containing histiocytes include verruciform xanthoma, xanthoma disseminatum (XD) involving the larynx and xanthoma or fibrous histiocytoma confined to larynx. ${ }^{1}$ V erruciform xanthoma is uncommon lesion and involves oral cavity, respiratory tract and external genitalia. On histology, papillary projection of surface squamous epithelium and xanthoma cells restricted to the connective tissue papillae between the epithelial rete ridges are seen. XD is normolipemic xanthomatosis, a rare disorder. In XD, skin is always involved and lesions are also present in other organs. When it involves larynx, multiple papules and nodules in the respiratory tract including thelarynx, in addition to multiple xanthomatous lesions are identified. Clinical features of XD include dyspnea, recurrent laryngitis and gastroesophageal reflux disease. ${ }^{2}$ In the present case XD was excluded due to absence of xanthomas of skin during the clinical follow-up. Verruciform xanthoma was excluded by absence of papillary projection on histopathological examination. We considered it as xanthoma confined to Iarynx after excluding fibrous histiocy toma because we did not get proliferation of fibroblastic cells with storiform or fascicular arrangement. The macroscopic view of xanthoma is usually a plaque; a papule or a nodule and sessile polypoidal structure similar to the present case in xanthoma is extremely rare. The biochemical composition of $L D L$, VLDL and HDL particle are unremarkable in these cases. ${ }^{1,3}$ Whereas, serum cholesterol and LDL value was found borderline elevated in the present case.

Prognosis of $X D$ is related to the mucous membrane manifestations and involvement of the upper respiratory tract. ${ }^{4}$ The response to any form of therapy in XD is unsatisfactory and resistant to treatment. ${ }^{3}$ Probucol, cholesterol synthesis enzyme inhibitors and glucocorticoid medication did not influence the xanthomas. ${ }^{3}$ H owever, case with extensive mucocutaneous, ocular, laryngeal, pituitary and central nervous system involvement, responded to treatment with cyclophosphamide is al so found. ${ }^{5}$ Occasional responses have been observed with the antilipemic agent clofibrate. A ntineoplastic agents including vinca alkaloids, alkylating agent and antimetabolites generally produce little objective responses. ${ }^{6}$ Surgery appears to give the best results for readily accessible lesions. ${ }^{6}$

\section{CONCLUSION}

$X$ anthoma rarely can affect larynx and mimic to laryngeal polyp clinically. Histopathological examination is must to establish the diagnosis and additional biochemical tests are helpful for further management in these cases.

\section{REFERENCES}

1. M atsumoto $T$, Nobukawa $B, K$ obayashi $K$, Watanabe $M$, Hosokawa A, Tomaru K, et al. Solitary polypoid xanthoma in the larynx. Histopathology 1999;34:475-77.

2. Perrone G, Zagami M , Casale M , Salvinelli F, M orini S, Rabitti C. Immunohistochemistry and differential diagnosis of a solitary flat laryngeal xanthoma: A case report. In Vivo 2007;21: 119-21.

3. Tietge UJ, M aschek $H$, Schneider A, Gawehn AE, W agner S, $M$ anns $M P$, et al. $X$ anthoma disseminatum with marked mucocutaneous involvement. Dtsch $M$ ed Wochenschr 1998;123:1337-42.

4. Davies CW H, M arren P, J uniper M C, Gray W, W ojnorowska $\mathrm{F}$, B enson M K . X anthoma disseminatum with respiratory tract involvement and fatal outcome. Thorax 2000;55:170-72.

5. Pruvost C, Picard-Dahan C, B onnefond B, G rossin M , G ehanno $P$, Souteyrand $P$, et al. V inblastine treatment for extensive non-X histiocytosis (xanthoma disseminatum). A nn Dermatol V enerol 2004;131:271-73.

6. A lexander AS, Turner R, U niate L, Pearcy RG. X anthoma disseminatum: A case report and literature review. $\mathrm{Br}$ J Radiol 2005; 78:153-57. 


\section{ABOUT THE AUTHORS}

\section{Anil Kumar Jain (Corresponding Author)}

A ssociate Professor, Department of ENT and Head and Neck Surgery, CU Shah M edical College, Surendranagar, G ujarat, India e-mail: draniljain91011@gmail.com

\section{Sanyogita Jain}

Tutor, Department of Microbiology, CU Shah Medical College Surendranagar, Gujarat, India

\section{Ashish Katarkar}

Professor, Department of ENT, CU Shah Medical College Surendranagar, Gujarat, India

\section{Noorain Alam}

Principal, Department of Speech and A udiology, CU Shah M edical College, Surendranagar, Gujarat, India

\section{Nayna Lakum}

Professor, Department of Pathology, CU Shah Medical College Surendranagar, Gujarat, India

\section{Pankaj Shah}

Professor and Head, Department of ENT, CU Shah M edical College Surendranagar, Gujarat, India

\section{Datt Modh}

Resident (2nd year), Department of ENT, CU Shah M edical College Surendranagar, Gujarat, India 